\title{
Design of Seamless Flanging Machine for Boiling Water Pot
}

\author{
Kong Jiali ${ }^{1,2, ~ a, ~ W a n g ~ G u i w e i ~}{ }^{1,2, b}$ \\ ${ }^{1}$ School of Mechanical Engineering, Shandong Huayu University of Technology, Dezhou 253034, China \\ ${ }^{2}$ Dezhou Municipal Key Laboratory of Industrial Robot Control, Dezhou 253034, China \\ akongjialiskd@126.com, bwgw1982.student@sina.com
}

Keywords: water pot, flanging machine, seamless, Soldworks

\begin{abstract}
With the improvement of people's living standards, aesthetic values and values, more and more boiled water pots emerge as the times require. One of the most critical processes is the flattening of the flanges in the pot, which restricted the quality and production of this kind of boiling water pot. An inner flanging seamless flatting machine is designed based on Soldworks. Practice and experiments show that the flanging machine completes the seamless flatting and ensures the quality and improves the production efficiency.
\end{abstract}

\section{Introduction}

Water pots is also named electric kettle or boiling kettle. The open-water pot shape is the cylinder as the common pot class, whose function is perfect [1]. Because of its convenience, the market demand for electric kettle is increasing day by day in recent years [2]. With the improvement of people's tastes, more and more boiling water pots have emerged, including a novel design, following the trend of the times of boiling water [3]. In order to prolong the service life of electric kettle, a new type of electric kettle with stainless steel drawing as inner tank is coming to market quietly [4]. Stainless steel kettle is a common stamping product in daily life. The shaping of the kettle body is a key problem in the process of punching production of the kettle [5]. And there is a most critical process, the most difficult process has been to restrict the quality of this kind of boiling water and the increase in output, this process is the flanging process. The existing levelling method is to put the pot body in boiling water pot on the die, through the hydraulic lever are 16 pieces of iron to open to the inner edge of the appropriate size and then pressure [6]. Because of the process of supporting the expansion of the tire, 16 pieces of iron between the size of the gap, the pressure is over, there are cracks in the local pressure uneven, which needs to rotate a certain angle to press once more. So the flanging is rough with poor quality, which cannot meet the needs of mass production. In addition, the expansion of tire production complex, it is difficult to achieve even rise, sometimes the gap is large in the place to reach $10 \mathrm{~mm}$, after pressing the pot body deformation is serious; a pot body needs to meet the requirements for several times with poor stability and low efficiency, which cannot meet the requirements of mass production, maintenance trouble, maintenance cycle long.

Based on the Soldwork software, it designs a flanging machine that are uniformly rising and contraction of the inner flanging seamless, solving this process, and guarantying the product quality, enhancing the product productivity.

\section{Conceptual design of flattening machine}

This equipment has the worktable part, the revolving integration part, the hydraulic drop down part and the electrical part, shown in Figure 1.

The workbench part has the frame and the platform composition. Its function is to support the whole equipment work, the platform has enough strength, which cannot be bent. The Rotary integration part has the turntable, the tensioner control (expansion tire, the slider and the turntable), the gear and so on. Its role is to drive the turntable rotation to make the combination of the tight 
round. The hydraulic pressure drop part has the press plate, the center axis, the hydraulic cylinder composition, whose function is to drive the tightening combination device to move up and down, the boiling water pot account inside flanging presses the flat. According to boiling water Pot flanging Machine's actual work and its characteristics, combined with the mechanical cost and easy repair, maintenance, easy use and other characteristics, the "motor-reducer-gear transmission" transmission plan is selected, the power of the motor through the reducer and then through the gear to power to the main shaft, to achieve the required dynamic conditions in the processing process.

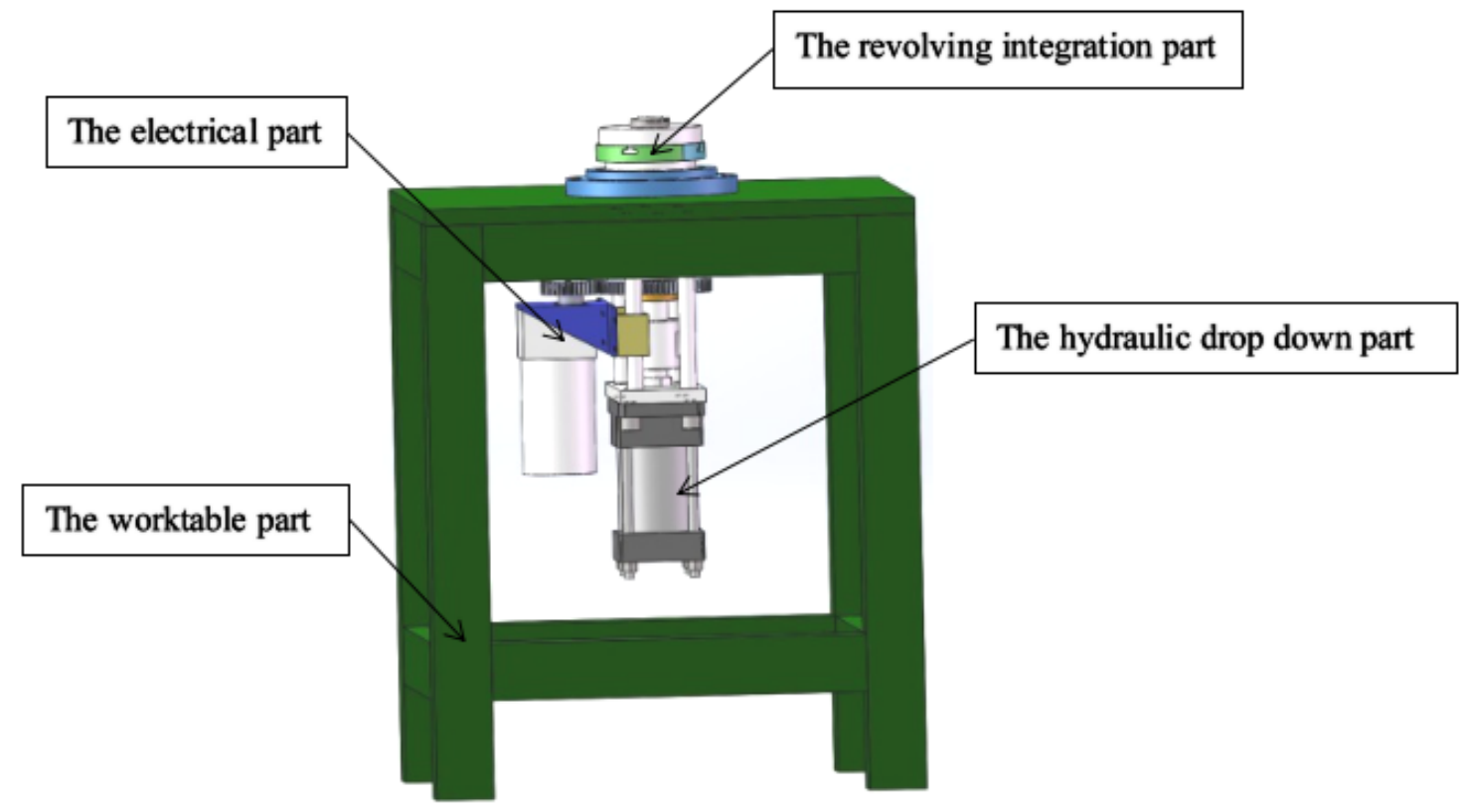

Figure1 Three-dimensional diagram of flanging machine

\section{Analysis of working process}

The cup of boiling water is lowered on the flange, press the Start button, at this time, the motor rotation, through the gear driven sleeve counter-clockwise rotation, the turntable is fixed on the sleeve, so the turntable also does counter-clockwise rotation, the pressure plate is fixed on the center axis, fixed, the pressure plate on the slide, the top of the sleeve on the slide. The lower end extends into the slot of the turntable, and when the turntable rotates counter-clockwise, expansion of the 4 parts will be in turn, forming a positive circular structure, the hydraulic cylinder down, driving the center axis downward movement, at the same time turntable, expansion tires, plate, nuts together downward movement, with the expansion of the bottom of the tire will be boiling water pot mouth inside flanging. 0.5 seconds after the pressure cylinder rise, driving the center axis upward movement, at the same time turntable, expansion tires, pressure plate, nuts together to move up, to the top, the motor reverse rotation, through the gear driven sleeve to do clockwise rotation, the turntable also do clockwise rotation, the expansion of the 4 parts will be in turn, forming smaller than the pot mouth structure, motor stop rotation, the workpiece is taken out, a crimping process is completed.

Through practice, the seamless machine can be automatic control, saving time and effort, to achieve more than one work together, a person to operate multiple machines, saving labor, the results of stability, good quality. One of the main parts is turntable, as shown in Figure 2, tensioner control in Figure 3, it achieves seamless flattening to deal with the traditional flap rising tight pressure edge wrinkling.

Automatic control saves time and labor, it achieves a number of working together. One person operates more than one machine, saving labor with flat stable results and good quality. It greatly solves the problems like existing dilatation tire making complex, difficult to achieve uniform expansion, easy to create large gaps, serious the pot body deformation after pressing, a kettle body needs several times to press to barely meet the requirements, poor quality stability, low efficiency. 
It can meet the requirements of mass production, maintenance trouble, long repair period, because of the addition of sliders and support, the design can support the motor, but also facilitate the movement of the motor. By adding a foot bolt and a hollow sucker, the design improves the support effect.

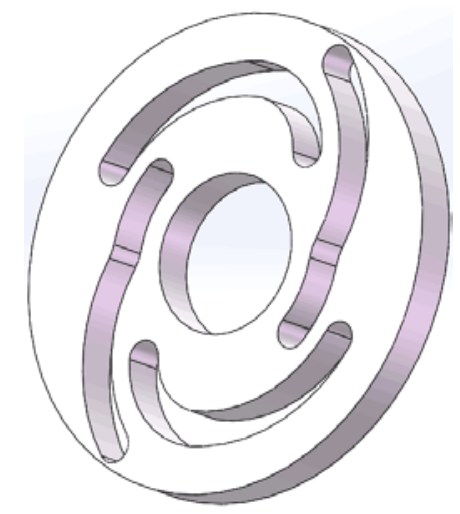

Figure2 Turntable

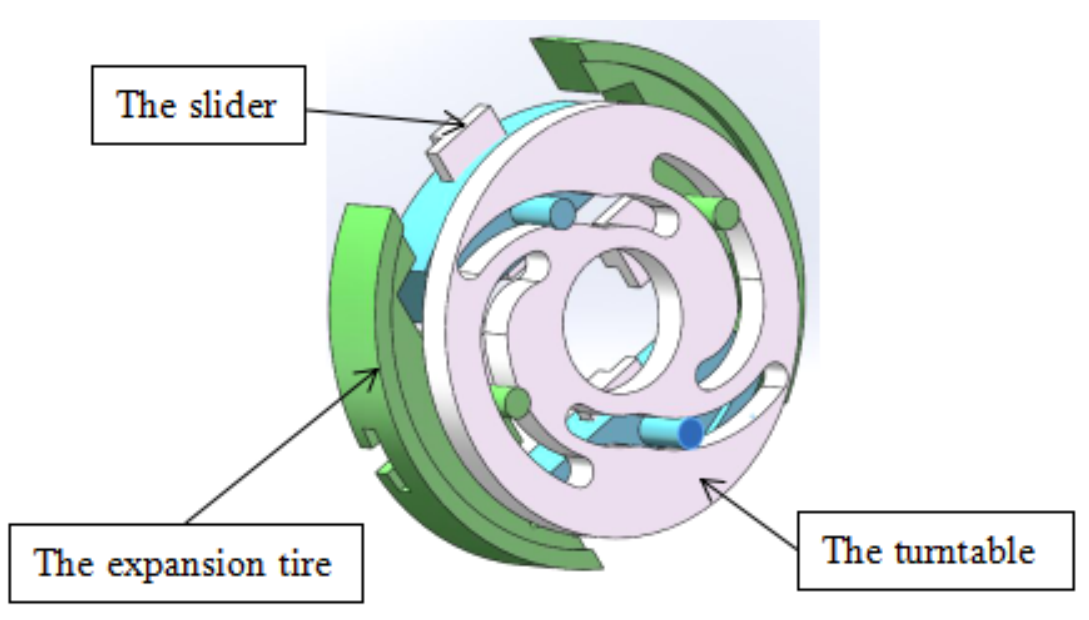

Figure3 Tensioner control

\section{Conclusions}

An inner flanging seamless flatting machine is designed based on Soldworks, which facilitates the placement of a water pot because of the addition of circular grooves and support gaskets. It prevents the slider from colliding with the support frame, and improves the sliding effect because the slide rail is added to the machine. Experiments show that the machine is easy to operate, and ensures the quality of boiling water pot.

\section{References}

[1] Xu Lan. (2010) Design of Student Machine for Open Water cooker,1-3.

[2] Lin Sixuan. (2009) An innovative design of electric kettle structure. Home appliance science and technology,34-35.

[3] Wang Lin. (1992) Exploration of metal barrel flanging machine. Chinese packing, 69-74.

[4] Hua Danhong, Lin Kang. (2007) Simulation Analysis of Die Design for Deep Drawing Parts of Electric Hot Water Bottle. Die and Mould Technology: 5: 52-54.

[5] Huang Yihong. (1994) Forming process and Die of stainless Steel kettle body. Metal forming machinery, 6, 41-44.

[6] Huang Chunfeng. (1997) Development of TF1200 full hydraulic barrel flanging Machine. Forging Technology, 5, 47-49. 